\title{
LXXII. A contribution to the study of the dielectric constant of water at low temperatures
}

\section{O.U. Vonwiller B.Sc.}

To cite this article: O.U. Vonwiller B.Sc. (1904) LXXII. A contribution to the study of the dielectric constant of water at low temperatures, Philosophical Magazine Series 6, 7:42, 655-662, DOI: $10.1080 / 14786440409463159$

To link to this article: http://dx.doi.org/10.1080/14786440409463159

曲 Published online: 15 Apr 2009.

Submit your article to this journal \lceil

Џll Article views: 8

Q View related articles $\square$

Citing articles: 1 View citing articles 5 
period of the free vibration when the distance between the ends exceeds $8 \mathrm{cms}$. Several attempts were made to determine the period of the free vibration of the resonator with bare ends close enough for a spark to pass between them, but they were unsuccessful.

The Physical Laboratory,

The University of Sydney,

December 8th, 1902 .

LXXII. A Contribution to the Studly of the Dielectric Constant. of Water at Low Temperatures. By O. U. VonwILLer, B.Sc., Demonetrator in Physies in the University of Sydney, N.S. $W$.*

THE experiments described in the following paper were carried out with the object of investigating the variation of the dielectric constant of water with temperature in the neighbourhood of $4^{\circ} \mathrm{C}$.

C. B. Thwing (Phys. Rev. ii. p. 35) carried out some experiments which apparently showed the existence of a critical point at $4^{\circ}$ C., the dielectric constant rising to a maximum value at that point and ihen decreasing as the temperature rose. On the other hand, Drude (Wied, Ann. lix. $1896^{\circ}$ ) and other experimenters have not observed such an effect.

The author's experiments were carried out with electrical oscillations having a frequency of about 25 millions per sec., produced in a Lecher wire-system by the oscillatory discharge of a condenser.

The arrangement of the apparatus is shown in fig. 1. A

Fig. 1.
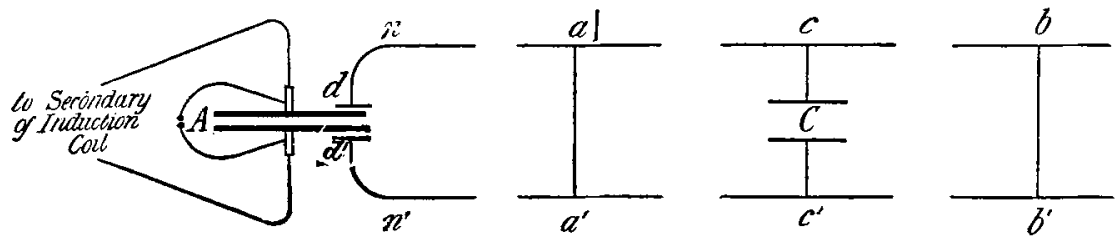

is a condenser consisting of two parallel circular brass plates, 30 centimetres in diameter, connected to the ends of the secondary of an induction-coil.

This condenser is discharged by means of a spark between two aluminium knobs immersed in kerosene, and joined to

* Communicated by the Author. Read before the Royal Society of New South Wales. 
the condenser plates by brass rods 3 millimetres thick and 30 centimetres long, bent into an approximately circular form. Two brass plates, $d d^{\prime}, 8 \cdot 8$ centimetres in diameter, are held 8 millimetres from the plates of $A$, and attached to them are brass wires $d b, d^{\prime} b^{\prime}, \cdot 36$ millimetre in diameter and 30 centimetres apart except the parts $d n, d^{\prime} n^{\prime}$, each 27 centimetres long, where the wires curve in. 'Two bridges of copper wire $a a^{\prime}$ and $b b^{\prime}$ are placed across these brass wires. The circuit $d a a^{\prime} d^{\prime}$ is called the Primary, and $a b b^{\prime} a^{\prime}$ the Secondary. Across the wires is placed a light wooden slider, the wires passing through small glass tubes attached to it; round each of these tubes is a single loop of wire which leads to the terminal of a Rutherford detector, the deflexions produced by which on a magnetometer were used in determining the character of the oscillations set up in the wires. The details of the detector and the method of using it are similar to those described by Prof. Pollock and the author in their experiments on Electric Wares in Short Wire Systems (Phil. Mag. June 1902).

With the bridge $a a^{\prime}$ at a distance of 170 centimetres from $n n^{\prime}$, the wooden slider carrying the detector being 5 centimetres from $n n^{\prime}$, the capacity of A was altered by varying the distance between the plates until the primary was in resonance with the condenser vibration, the deflexions produced by the detector being greatest when this is the case.

The effective length of the primary is now $\frac{\lambda}{2}$, where $\lambda$ is the wave-length of the condenser radiation. By altering the position of the bridge $b b^{\prime}$ the secondary can be brought into resonance with the primary, this being the case when its effective length is $\lambda$, the correct position being determined by keeping the slider midway between the two bridges, $i$. $e$. at a loop of the wave, and altering the length of the circuit until a maximum deflexion is obtained.

In these experiments a condenser $C$ was placed across the wires of the secondary at, some place $c c^{\prime}$. The effect of this capacity is equivalent to an addition to the length of the wires, the wave-length of free vibrations in the eircuit $a b b^{\prime} a^{\prime}$ being given by $\lambda$ in the equation

$$
\cot \frac{2 \pi a}{\lambda}+\cot \frac{2 \pi b}{\lambda}=\frac{2 \pi}{\lambda} \frac{\mathrm{C}}{s},
$$

as shown by Morton (Phil. Mag. May 1897). $a$ and $b$ being the distances from the middle points of the bridges $a a^{\prime}$ and $b b^{\prime}$ respectively to the condenser, $\mathrm{C}$ the capacity of the 
condenser, and $s$ the capacity per unit length of the two parallel wires.

If the secondary is in resonance with the primary, a change in the capacity of $\mathrm{C}$ will throw it out of resonance, and the deflexions produced by the detector will be smaller. An investigation of Morton's formula shows that a given percentage change of capacity produces the greatest proportionate change in the effective length of the circuit when $a=b=\lambda / 8$, the effect of the capacity being thus equivalent to an addition of $\lambda / 2$ to the length of the circuit.

It has always been observed, however, that when the primary and secondary are in resonance a comparatively great change in the effective length of the secondary is necessary to produce an appreciable change in the deflexion; but when the two circuits are not in tune, the deflexions vary by a considerably greater amount for a given alteration of length of secondary.

In order to determine the couditions under which the greatest change in deflexion results from a given percentage change in the capacity of $\mathrm{C}$, a series of trials was made with an air-condenser consisting of two circular zinc plates 30 centimetres in diameter, the capacity of which was varied by altering the distance between the plates. In these trials $a$ and $b$ were given various values, and as a result it was found that the highest degree of sensitiveness was $o b-$ tained when $a=b=\frac{\lambda}{8}$ approximately, the capacity being much too large to give good resonance.

With this arrangement the slider with the detector was ylaced close to the condenser, the detector was thus practically about halfway between the bridge and the middle of the circuit, $i$. e. halfway between a node and a loop of the wave, and so the deflexions obtained were really considerably smaller than if it could have been placed at the loop.

A condenser with water as its dielectric was now attached to the wires in the position where the best results were obtained with the air-condenser: here $a=b=300$ centimetres, and the slider was between $a$ and $c$ and distant 5 centimetres from the latter point. The condenser consisted of two wires similar to the main wires, and each 25 centimetres long. These wires first ran horizontally towards one another and then were bent vertically downwards at a distance varying in different experiments from 9 to 11 centimetres apart, dipping into water placed in a large glass vessel.

With the water at the temperature of the room, the depth to which the wires were immersed was varied by increasing

Plic. May. S. 6. Vol. 7. No. 42. June 1904. 2 Y 
or decreasing the amount of water in the vessel, and so varying the capacity. The depth was altered until the deflexion obtained was about the same as that obtained with the air-condenser when its capacity was such that the arrangement was in its most sensitive state. The water was then removed and ice-cold water poured into the vessel to the same level, and readings taken at frequent intervals as the temperature rose, the temperature of the water being observed on two mercury thermometers, and the water being continually stirred.

As the temperature rose the change of capacity was indicated by a change in deflexion. Between $0^{\circ}$ and $15^{\circ}$ there was on the whole a decided increase in deflexion, showing a decrease in capacity ; but in these earlier experiments, owing to irregularities in sparking it was impossible to say definitely whether the deflexion at $4^{\circ}$ was higher or lower than that at $0^{\circ}$, the variation in successive sparks being so great as to mask the change between these points.

On several occasions there appeared to be an indication of a minimum deflexion in the neighbourhood of $4^{\circ}$; but on other trials, apparently equally reliable, this result was not obtained. In any case the variation of capacity necessary to produce the apparent change would have been very smallmuch smaller than that obtained by Thwing, which would have produced an unmistakable change.

Single sparks only were taken, the deflexions thus obtained being more regular on the whole than those in which a series of sparks were taken for each observation.

In order to obviate this variation of deflexion due to the irregular sparking, another slider and detector were placed near the open end of the primary, and the deflexions produced by this detector on a second magnetometer were observed. These deflexions should have been constant. With the secondary unchanged, when a series of readings were taken, although the deflexions produced by either detector varied considerably, the ratio of the two deflexions was found to vary to a much less extent.

The following table shows a set of four readings of deflexions of primary and secondary detectors, and the ratio of the two, no change being made during the four readings:-

\begin{tabular}{|c|c|c|}
\hline$\delta_{\mathrm{P} \cdot}$ & $\delta_{\mathrm{S}}$ & $1000 \delta_{\mathrm{S}} / \delta_{\mathrm{P}^{*}}$ \\
\hline $31 \cdot 5$ & $28 \cdot 7$ & 911 \\
$3 \cdot \cdot 1$ & 33.5 & 903 \\
$34 \cdot 4$ & $31 \cdot 8$ & 924 \\
$32 \cdot 5$ & $29 \cdot 6$ & 911 \\
\hline
\end{tabular}


$\delta_{\mathrm{P}}$ being the deflexion produced by the detector in the primary, and $\delta_{\mathrm{S}}$ the deflexion produced by the detector in the secondary.

Accordingly, in subsequent experiments the deflexions produced by detectors in both primary and secondary were taken after each spark, and the variation of the ratio of the two observed.

These experiments all indicated a continuous fall in capacity as the temperature rose, at least no marked critical point at $4^{\circ} \mathrm{C}$. being shown.

In order to ascertain the extent of the change of capacity, a condenser consisting of two circular brass plates, $30 \cdot 2$ centimetres in diameter and 7.55 centimetre thick, which could be moved apart in a direction perpendicular to their planes, was substituted for the water condenser, and observations were taken with the plates at different distances apart. The capacities at these distances were calculated by Kirchhoff's formula :

$$
c=\frac{r^{2}}{4 a}+\frac{r}{4 \pi \alpha}\left\{-a+a \log \frac{16 \pi r(a+d)}{a^{2}}+d \log \frac{a+d}{d}\right\},
$$

where $r$ is the radius of the plates, $a$ their distance apart, and Fig. 2.

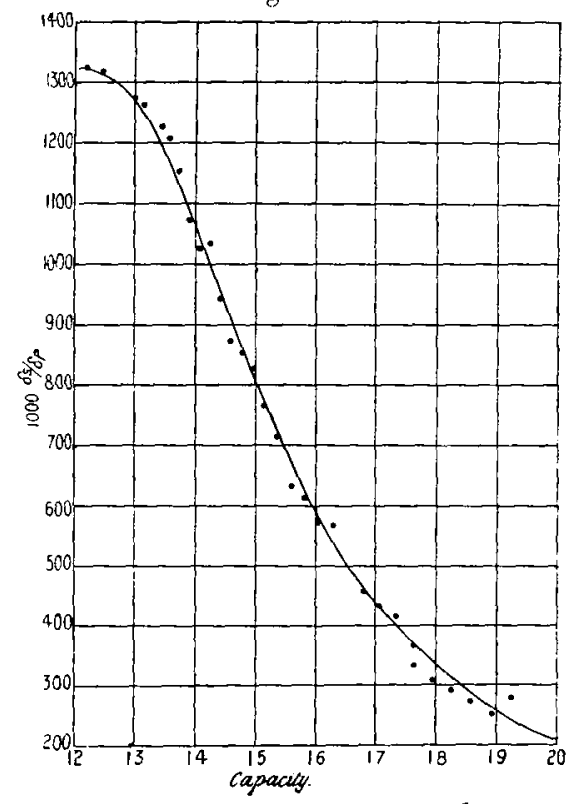

$d$ their thickness; and the resulting curve between capacities and the ratio $1000 \lambda \delta_{\mathrm{S}} / \delta_{\mathrm{P}}$ is shown in fig. 2. This curve 
shows how the sensitiveness for a given change of capacity decreases as we approach the position of resonance.

Figs. $3,4,5$, and 6 were now drawn, in which the abscissæ represent temperatures, and the ordinates the capacities of

Fig. 3.

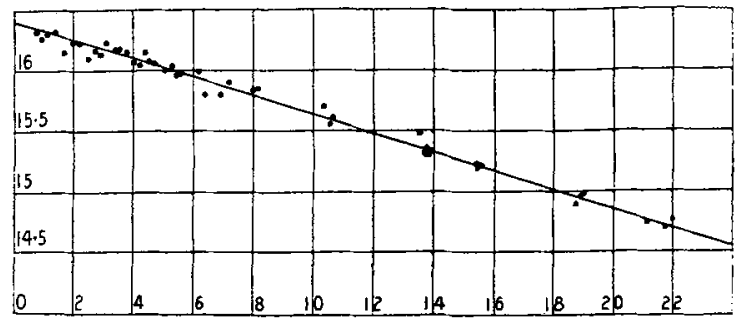

Fig. 4.

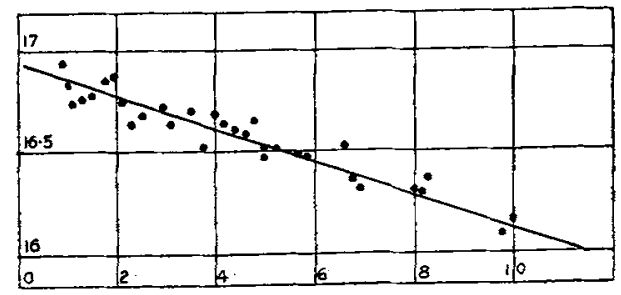

Fig. 5.

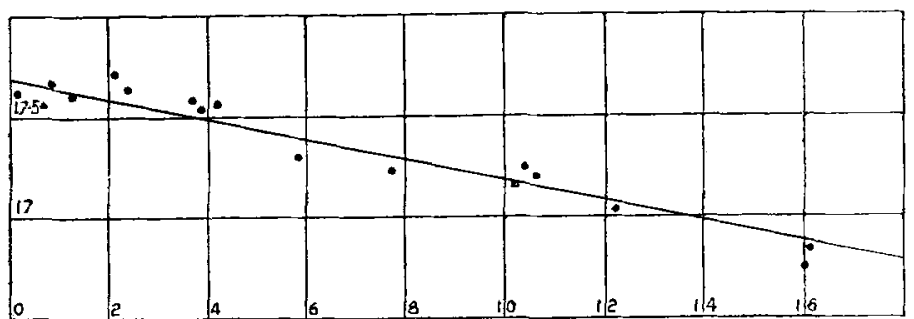

Fig. 6.

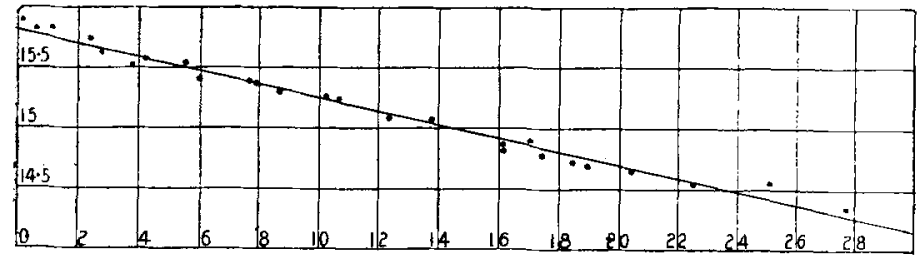

the water-condenser, the capacities being obtained from the curve in fig. 2 for the values of $1000 \times \delta_{\mathrm{s}} / \delta_{\mathrm{P}}$ obtained at 
the various temperatures. In all these curves there is to be noticed a decided fall in capacity as the temperature rose; and the curves are practically straight lines.

The change of capacity for $1^{\circ}$ rise in temperature, expressed as a percentage of the capacity at $0^{\circ} \mathrm{C}$, obtained from the different curves is :

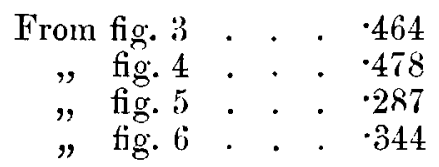

The dielectric of the condenser consisted partly of air and partly of water, the wires being out of the water for a considerable part of their length; and as the variation affected only the water, the total percentage change of capacity is less than that of the dielectric constant of the water.

In the first two trials recorded above the water was placed in a large glass vessel 25 centimetres square, and the depth of water in it was about 15 centimetres; but in the other two the water was placed in a beaker 15 centimetres in diameter and the depth of water was about 15 centimetres: so in this case the air would have a greater relative share in the whole effect, and the observed change is less than in the former trials, where the variation in capacity is probably very nearly equal to the variation in the dielectric constant of water. In all four trials the wires were immersed to a depth of 5 or 6 centimetres, and were from 9 to 11 centimetres apart.

The assumption bas been made that when the same deflexion is obtained with the water-and air-condensers, the capacities are the same. By removing water from the vessel, and so decreasing the capacity, we can come into a position of resonance ; and it was found that the maximum deflexions obtained when this was done were practically the same as the greatest deflexions obtained with the air-condenser, and so the conductivity of the water has no appreciable effect and the above assumption is probably permissible.

The specific conductivity of the water was measured, and found to be $3.7 \times 10^{-6}$ at $18^{\circ} 8 \mathrm{C}$.

These results show no indication of the large effect observed by Thwing at $4^{\circ} \mathrm{C}$. With the exception of the results shown in fig. 5 , all the observations are definitely lower at $4^{\circ}$ than at $0^{\circ}$. According to Thwing the dielectric constant at $0^{\circ}$ is 79.4 and at $4^{\circ} 85 \cdot 20, i$. e. it increases by 7.2 per cent. In fig. 3 the capacity at $0^{\circ}$ is 16.39 ; if it were $7 \cdot 2$ per cent. higher at $4^{\circ}$, the capacity would be 17.51 at that temperature. 
An inspection of the curves shows that any change of that order could not fail to be detected.

In conclusion, I desire to express my best thanks to Professor Pollock for many valuable suggestions and for his continued encouragement during the work.

The University of Sydney.

\section{On the Vapour-Pressure of Mercury at Ordinary} Temperatures. By EDWARD W. MoRLeY *

TN 1890, when attempting to determine the density of 1 hydrogen with accuracy, it became convenient to know the vapour-pressure of mercury at ordinary temperatures. There were extant two series of actual measurements at such temperatures, and four computations of the desired values from extrapolation formulæ founded on observations at higher temperatures.

The first of these computations was due to Regnault $\dagger$, and was published by him in 1862. A second and a third were published by Hagen $\ddagger$ and by Hertz $\S$ in 1882. Ramsay and Young |l published the fourth in 1886 .

Regnault also made a few observations at temperatures below $100^{\circ}$, which were published with those mentioned above. They seem to have been of service only in guiding conjecture as to the vapour-pressure which was assumed for $0^{\circ}$. Lastly, van der Plaats $\uparrow$ in 1886 published direct determinations of the vapour-pressure at $0^{\circ}$ and at the temperature of his laboratory.

The following table gives the vapour-pressure of mercury at certain temperatures according to these authorities :-

\begin{tabular}{|c|c|c|c|c|c|}
\hline Temp. & Regnault. & Hagen. & Hertz. & $\begin{array}{c}\text { Ramsey \& } \\
\text { Young. }\end{array}$ & $\begin{array}{l}\text { vau der } \\
\text { Plaats. }\end{array}$ \\
\hline $\begin{array}{r}8 \\
10 \\
20 \\
30 \\
40 \\
50\end{array}$ & $\begin{array}{c}\text { mm. } \\
0.0200 \\
0.0268 \\
0.0372 \\
0.0530 \\
0.0767 \\
0.1120\end{array}$ & $\begin{array}{l}\text { mm. } \\
0.015 \\
0.018 \\
0.021 \\
0.026 \\
0.033 \\
0.042\end{array}$ & $\begin{array}{l}\text { mm. } \\
0.00019 \\
0.0005 \\
0.0013 \\
0.0029 \\
0.0063 \\
0.013\end{array}$ & $\begin{array}{c}\text { min. } \\
\cdots \\
\cdots\end{array}$ & $\begin{array}{c}\mathrm{mm} . \\
0.0047 \\
0.008\end{array}$ \\
\hline
\end{tabular}

* Communicated by the Author.

+ Relation des Expériences, ii. p. 506.

Wiedemann's Annalen, xvii. p. 618.

\$ Ibid. xvii. p. 197.

॥ Chem. Soc. Journal, xlix. p. 37.

IT Recueil des Travaux Chimiques des Pays-Bas, v. p. 149. 